\title{
تحليل حروف الواو في سورة الواقعة وإستراتجيتها في تعليم اللغة العربية
}

${ }^{1}$ Siti Sumaiah, ${ }^{2}$. Ali Asrun Lubis S.Ag., M.Pd

Sumayyahbatubara02@gmail.com

Pendidikan Bahasa Arab IAIN Padangsidimpuan

$$
\begin{aligned}
& \text { القواعد في اللغة العربية لما مكان مهم ووتأخذ أساسا للقواعد من القرآن وقد توجد البحث في القواعد } \\
& \text { عن الحروف ومنها حرف الواو وتقع البحث في سورة الواقعة، المسئلة في هذا البحث هو كيف كانت صياغة } \\
& \text { حروف الواو في سورة الواقعة وكيف إستراتيجية تعليمه في تعليم اللغة العربية. هذا البحث هو البحث النوع بمنهج } \\
& \text { الدراسة المكتبية. النتائج من هذا البحث وجدت الباحثة حروف الواو في سورة الواقعة 43، فهو من واو العطف } \\
& \text { واو القسم واو الحال واو الزيداة، حروف الواو من واو العطف جملتها مب، وحروف الواو من واو القسم ال، } \\
& \text { وحروف الواو من واو الحال س، وحروف الواو من واو الزيداة له وأختر الباحثة إستراتيجيت تراكيب. } \\
& \text { كلمات المفتح : حروف الواو؛ سورة الواقعة؛ إستراتيجيت تعليم }
\end{aligned}
$$

\begin{abstract}
Abstrak
Kaedah dalam Bahasa Arab memiliki peran utama, dasar penetapan kaedah ini adalah Alquran, salah satu bahasan dalam kaedah Bahasa Arab adalah bahasan tentang huruf, termasuk bahasan tentang huruf waw. Masalah Penelitian ini adalah bagaimana bentuk huruf waw pada surat al-waqi'ah dan bagaimana strategi pembalajarannya dalam pembelajaran Bahasa Arab. Penelitian ini adalah metode kajian kepustakaan. peneliti menemukan huruf wau di suroh al-waqi'ah sebanyak 43 dan wa'u di situ waw a'thof, waw qosam, waw hal, waw zaidah. wau athof sebanyak 38 sedangkan waw qosam 1, waw hal 3 dan waw zaidah 1 . Kemudian peneliti menggunakan strategi tarokib atau penyusunan keedahnya masing-masing dalam pembelajarannya.
\end{abstract}

Keyword : Huruf waw; Surat al-Waqi'ah; Strategi pembelajaran 
Thariqah IImiah: Jurnal IImu-IImu Kependidikan \& Bahasa Arab edisi juni 2021

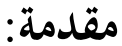

نزل القرآن على محمد صلى الله عليه وسلم لا على قلبه، لكن خص القلب بالذكر لأن

السبب في تمكنه صلى الله عليه وسلم من الأداء ثباته في قلبه، فمعنى على قلبك حفظه إياك وفهمه. وقيل : أي جعل قلبك متصفاً بأخلاق القرآن ومتأدباً بآدابه كما في حديث عائشة كان خلقه صلى الله عليه وسلم القرآن وكان حق الكلام أن يقال على قلبي إلا أنه جاء على حكاية كلام الله كما تكلم به كأنه قيل : قل ما تكلمت به من قولي " من كان عدواً لجبريل فإنه نزله على قلبك " ومعنى " مصدقاً لما بين يديه " موافقاً لما قبله من كتب الأنبياء فيما يرجع إلى المبادئ والغايات دون الأوساط التي يتطرق إليها الاختلاف بتبدل الأزمان والأوقات.' القران يتكون من ع || سورة و اله ب7 إيه. الآيات التي تنزل قبل النبي هاجر إلى المدينة المنورة كانت تسمي مكية التي شملت حوالي ثلثي رسالة القنطرة بأكملها، في حين ان آيات التي نزلت بعد ان هاجر النبي إلى المدينة المنورة كانت تسمي المدائن التي شملت حوالي ثلث رسالة كامله من القران. ورد في حديث رسول الله صلى الله عليه وسلم في رواية جابر بن سمّرَة يقول: كان رسول

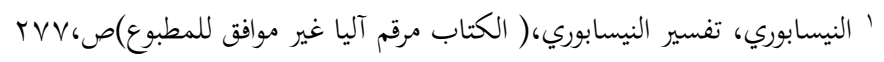

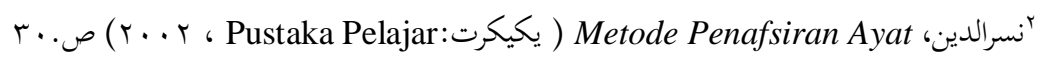


Thariqah IImiah: Jurnal IImu-IImu Kependidikan \& Bahasa Arab edisi juni 2021

الله صلى الله عليه وسلم يصلي الصلوات نحو من صلاتكم التي تصلون اليوم، ولكنه كان يخفف. كانت صلاته أخف من صالكمم، وكان يقرأ في الفجر "الواقعة" ونخوها من السور.r اللغة هو ألفاظ يعبر بها كل قوم عن مقاصدهم. واللغات كثيرة، وهي مختلفة من حيث اللفظ، متحدة من حيث المعنى، أي: ان المعنى الواحد الذي يخالج ضمائر الناس واحد، ولكن كل قوم يعبرون عنه بلفظ غير لفظ الآخرين. فالكلمة في اللغة العربية تنقسم إلى اسم و فعل و حرف. معنى الإسم هو كلمة تدل بذاتما على شيئ مخصوص (مثل بيت، كرسي، جمل)، او شيئ غير خصوص يعرف بالعقل (مثل شجاعة، ثقافة، مروءة) ولا يقترنان بزمن · ويقال ايضا هو كل كلمة تدل على إنسان او حيوان او نبات او جماد او مكان او زمان او صفة او معنى بجرد من الزمان. مثل: رجل،زهرة، اسد، ومسجد. والفعل هو كل كلمة تدل على حدوث شيئ في زمان خاصّ. مثل : نصر ينصر انصر. وأماالحرف هو كل كلمة ليس لها معنى إلا مع غيرها. و الواو من الأحروف التى ذات إفادة "مطلق الإشترك والجمع" في المعنى بين المتعاطفين إن كانا مفردين. الحرف هو مبني ومعاني، مبني يعني غير معنى اذا لا يوجد حرف الزيدة، والمعاني يملك من المعنى اذا يواصل من الحرف الزيدة او حرف المساعدة نحو، والله على كل شئ قدير. تنقسم الجملة

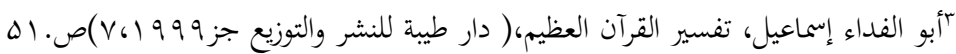

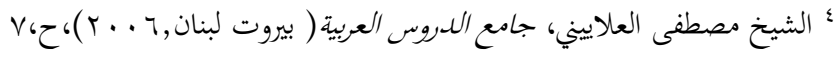


Thariqah IImiah: Jurnal IImu-IImu Kependidikan \& Bahasa Arab edisi juni 2021

في علم النحو إلى ثلاثة، وهي الاسم، والفعل، والحرف. فالاسم هو كل لفظ يسمى به إنسان أو حيوان أو نبات أو جماد أو أي شى اخر. والفعل هو كل لفظ يدل على حصول عمل في زمان خاص. والحرف هو كل لفظ لايظهر معناه كاملا الا مع غيره. 'معنى من الاسم يعنى الكلمة يوجد معنى نحو، اذا نديتم من الاسم عرفت، والاسم يوجد إلى الحيوان وغير ذالك.والفعل يعنى فعل ماض نهو قرأ، مضارع نحو يقرء،أمرنحو إقرء، والحرف يعني الة للقرئة. حرف الواو هو أحد الحروف المعانى لأن له معنى ظاهرا إذا اتظم في الجملة. و الحرف معانى ينقسم على قسمين هما حروف العملة و غير العملة. لحروف الواو أنواع متنوعة وينقسم حرف الواو إلى عشرة أنواع وهي واو قسم، واو عطف، واو الاستفناف، واو الحال، واو المعية، واو رب, او و التي حسب ماقبلها، واو ثثانية، واو الجمع المذكر السالمهواو الاسماء الخمسة. v فإن الأساس الأول لأخذ تعلم اللغة العربية هو علم النحو وعلم الصرف. علم النحو هو أحد فروع علوم اللغة العربية الذي يبحث عن كيفية تركيب الجمل التي تناسب بقواعد اللغة العربية، سواء المتعلقة بمكان الكلمات في الجملة أو حالة الكلمات (حركة النهائية والصيغة) في الجملة.كما "' Universitas Pendidikan )،Analisis Fungsi Dan Huruf Wawu Dalam Alqur'an "

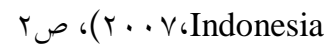

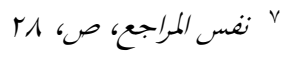


Thariqah IImiah: Jurnal IImu-IImu Kependidikan \& Bahasa Arab edisi juni 2021

قال الهاشيمي: النحو هو قواعد يعرف بها أحوال أواخر الكلمات العربية التي حصلت بتركيب بعضها مع بعض من اعراب و بناء وما يتبعهما.^ والعطف نوعان عطف بيان وعطف نسق، فالعطف البيان هو التابع المشبه للنعت في توضيح متبوعة إن كان معرفة نحو أقسم بالله أبو حفص عمر وتخصيصه إن كان نكرة نحو هذا خاتم حديد بالرفع ويفارق النعت في كونه جامدا غير مؤول بمشتق والنعت مشتق أو مؤول بمشتق وبواقف متبوعه في أربعة من عشرو في واحد من أوجه الإعراب الثلاثة وفي واحد من التطكير والتأنيث وفي واحد من التعريف والتنكير وين واحد من الإفرتد والتثنية والجمع ويصح في عطف البيان أن يعرب

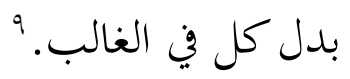
أما العطف النسق فهو التابع الذي يتوسط بينه وبين مطبوعه حرف من هذه الحرف العشرة وهي الواو والفاء وثم وحت وأم وأو وأما وبل ولا ولكن فالسبعة الأولى وتقتضى التشريك في الإعراب والمعنى والثلاثة الباقية تقتضي تشريك الإعراب فإن عطفت بها على مرفوع رفعت أو على منصوب نصبت أو على مخفوض خفضت أو على مجزوم جزمت نخو صدق الله ورسوله ومن يطع الله ورسوله ونحو وإن تؤمنو وتتقوا يؤتكم ولو يسألكم أموالكم. .'

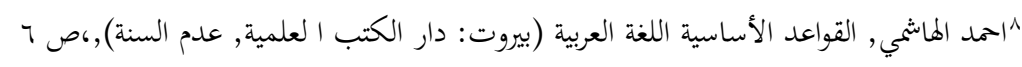

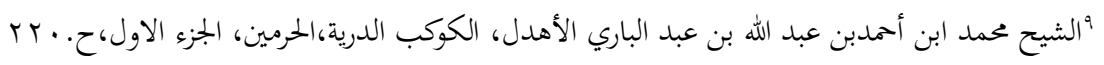

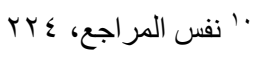


واو الحال: ما يصح وقوع (اذا ) الظرفية موقعها، فإذا قلت: (جئتُ والشمسُ تغيبُ) ضََّ

أن تقول: جئتُ والشمسُ تغيب). ولا تدخل إلآعلى الجملة، كما رأيتَ، فلا تدخل على حال

مفردة، ولا على حالٍ شِبهِ جملة. وأصلُ الربطِ أن يكون بضمير صاحب الحال. و حيث لا ضميرَ،

وجبتِ الواو، لان الجملة الحلية لا تخلو من أحدهما أو منهما معا. فإنكانت الواو مع الضمير، كان الربطُ أشََّ وأحكم. واو الحال، من حيث اقترانُ الجملة بها وعدمُهُ، على ثلاثة أضرُبٍ: واجبٍ وجائزٍ ومتتنع." واو الحال يبين من الحال او حال من المكان، اذا يوجد نهو حرّ و هذا ليس من الكلمات حال لكن يدخل الي مفرة، لماذا لأن الكلمات غير كاملا. واو الحال طابعا ليملك كلمات مراتب و

واو الحال: وهي يربط بين صاحب الحال وبين جملة الحال سواء كانت اسمية أم فعلبة (فيما

عدا الجملة الفعلية التي تبدأ بفعل المضارع مثبت) وتكون الجملة التي تليها في محل نصب حال. واو الحال: وتقدر بمعنى: (إذ)، وتدخل على الجملة الاسمية أو الفعلية، نهو : (عاد المعلمُ والفرحُ بادِعلى محيّاه) نحو قوله تعإلى: (لا تقربوا الصلاة وأنتم سكارى) ونحو (عاد خالدٌ وقد غابت الشمسُ)، الواو حالية، حرف مبني على الفتح لامحل له من الإعراب. والجملة بعدها في محل نصب الحال. r' 
واو الحال يجوز بالإسمية أو فعلية في اي مراتب إلى الكلمات او من القاعدته، واو الحال يدخل إلى جملة لإسمية او جملة الافعلية، و في أي يدخل هذا الكلمات.

الحال هو الاسم المنصوب المفسر لما انبهم من الهيئات نحو قولك:جاء زيد راكبت وركبت

الفرس مسرجا، ولقيت عبد اللهراكبا وما اشبه ذالك. ولا يكون الحال الا نكرة ولايكن الا بعد تمام

$$
\text { الكام ولا يكون صاحبها الا معرفة. }
$$

واو القسم: حرف جر، يجر الاسم الظاهر لا الضمير، وجوابه لا يكون إلا جملة خبريّة،

متعلق بفعل القسم المحذوف، نحو: واللهِ، و: الواو حرف جر وقسم مبني على الفتح لا محل له من الإعراب، متعلق بفعل القسم المحذوف، وتقد يره: أقسم. اللِّ: لفظ الجلالة، اسم مجرور بالكسرة الظاهرة. 'واو القسم وهو تدخل إلى لفظ الجلالة، وهذا حرف القسم ليس الواو فقط، يوجد ب، ت، نحو: بالله، تالله، و قسم تسميت الرف القسم.

الواو التي للقسم، اسم أقيم مقام المصدر وكثر استعماله فيه والفعل أقسم ومصدره الحقيقي الإقسام والذي ذكره كثير من أئمة اللغة أن القسم مأخوذ من أيمان القسامة وهي التي يحلف بها في

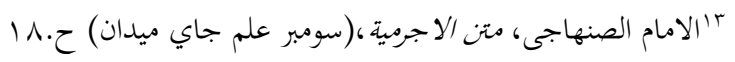

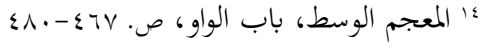


Thariqah IImiah: Jurnal IImu-IImu Kependidikan \& Bahasa Arab edisi juni 2021

القتل ثم إنه قيل لكل يمين قسم وهذا فيه نظر من وجهين أحدهما أن أصل القسامة مبدؤه من فعل

$$
\text { أبي طالب بسبب الأجير.10 - 20 - 10 }
$$

مزيدة في بناء الكلمة فإها لا تزاد أولا إذ لو زيدت أولا لم تكن إلا متحركة فإنه لا يبتدأ بساكن وحينئذ فأما أن تكون مفتوحة أو مضمومة أو مكسورة فلو زيدت مضمومة لساغ قلبها همزة واطرد ذلك فيها كما قالوا أقتت في وقتت وأجوه في وجوه."17 واو المزيدة ليس يوجد معنى معين، الا لزيدة فقط، وهذا واو ليعمل ليس يوجد لتغير من المعنى في هذه الكلمات. إذا كان مع الواو حرفان فقط قضي عليها بالأصالة إذ لا بد في الكلمة من ثلاثة أحرف وتقع حينئ فاء وعينا ولأما نحو وعد وموت ودلو وإن كان معها أزيد من حرفين فأما أن يكون معها ثلاثة أحرف مقطوع بأصالتها أو حرفان مقطوع بأصالتهما وما عداهما مقطوع بزيادته أو يكون ما عداهما محتملا للأصالة والزيادة. ل' واو المزيدة في ثلاثة أحرف وتقع حينئذ فاء وعينا ولأما نحو وعد وموت ودلو عداهما محتملا للأصالة والزيادة.

استراتيجيت تعلم اللغة العربية هي سلسلة من الجهود التي يمعلم مدرس اللغة العربية لجعل عملية التعلم تعمل وفق مفاهيم محددة مسبقاً. المفهوم الذي سيتم إنشاؤه من قبل المعلمين هو مفهوم فكيمي خمبروت، وهو التعلم الفعال والتواصلية والمخابرة، وفِّال، والمهببة، والمبهجة والمرجحة.

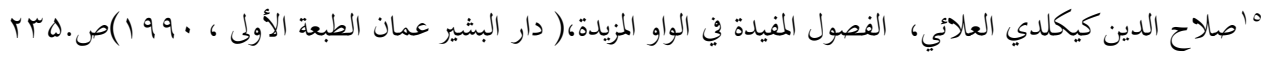

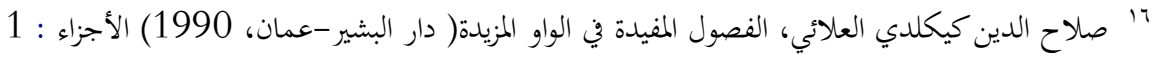

$$
\begin{aligned}
& \text { لا'نفس المراجع، الأجزاء : } 1
\end{aligned}
$$


Thariqah IImiah: Jurnal IImu-IImu Kependidikan \& Bahasa Arab edisi juni 2021

استراتيجية التعلم التي يقدمها هذا المعلم العربي يجب أن تكون قادرة على خلق ظروف تعلم الطلاب مثل المفهوم أعلاه، بحيث لا يحدث ذلك مرة أخرى^'.

يقصد بالاستراتيجيت بصفة عامة، فن اسخدام الإمكانات والوسائل المتاحة بطريقة مثلى،

تحقق الأهداف المرجوة على أفضل وجه. وفي التدريس يقصد باستراتيجيت التدريس هي مجموعة من الخطوات والإجراءات التي يقوم بها المعلم لتحقيق أهداف التدريس، وتشتمل هذه الاستراتيجية علي تميد للدرس يثير دافعية الطلاب للتعلم، وتحديد تتابع الأنشطة التعليمية التعلمية التي تتيح تحقيق الأهداف المرجوة، بما تتضممنه تلك الأنشطة من تحديد لأدوار الشاركين فيها (المعلم، الدارسين) والوسائل والمواد التعلمية، والطرائق ولأساليب التدريسية، وأنواع التعزيز المتبعة، والوقت المخصص لكل منها، وأساليب التقويم التكويني والختامي.19

الاستراتيجيت هو الالة المدة لي تعليم في الفصل وهذا يعملون إلى معليم أو معلمة لكي الطالب والطالبة مفهوم من الدرس، وهذا الاستراتيجيت لتعليم كيف يعليم حسنا و أسليب التقويم ومراتب الوقت الدرس الة الطلاب و الطالبة. 
Thariqah IImiah: Jurnal IImu-IImu Kependidikan \& Bahasa Arab edisi juni 2021

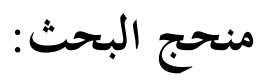

هذه الدراسة، نوع البحث المستخدم هو بحث المكتبية، وهو البحث الذي يقوم ليطالع الكتب والكتابات المتعلقة بالموضع المبحوث من البيانات الأولى والبيانات الثانوية. هذا البحث يسمى بحث المكتبية ييحث عن الكتب و لابد يذهب إلى مدرسة الأخر او

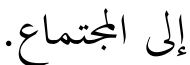

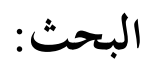

\section{1. المروف الواو في سورة الواقعة}

واو العطف هو يوجد من عطف النسق وعطف البيان، أما عطف النسق هو الكلمات تابعه

إلى مطبوعه نهو: وَبُسَّبِ الجُبِبالُ بَسَّا أو من مثال جاء زيد وخالد. وأما عطف البيان هو الكلمات

تابعه وبيانه إلى مطبوع الجمعه ولا يستطيع أن تأويل إلى المستقه، وبينه لازيع يراتب بين الاعراب

معريفة ونكيرة أو مذكر ومؤنث أو تسنية وجمع، نحو: العسجد الذهب، هذا فرق بين عطف النسق

وعطف البيان.

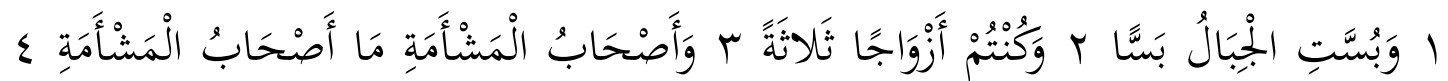

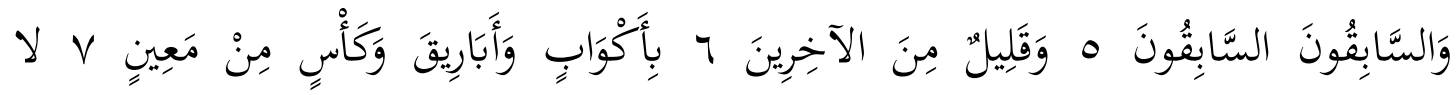

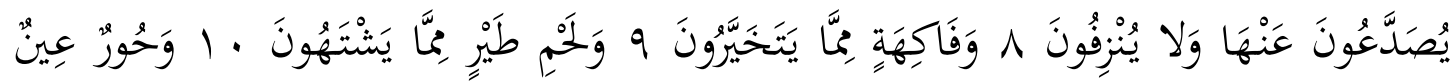

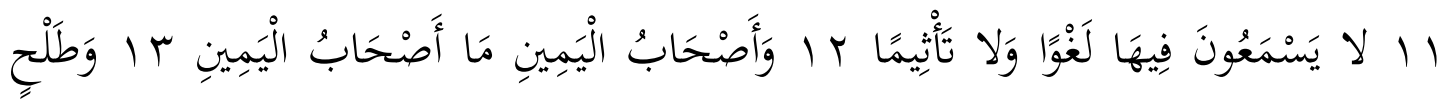

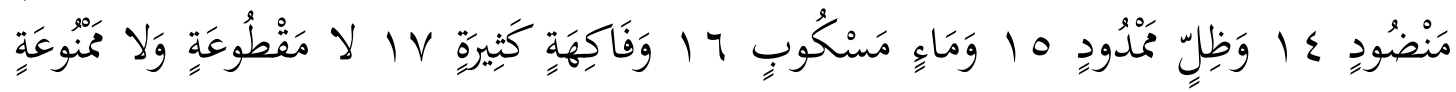


Thariqah IImiah: Jurnal IImu-IImu Kependidikan \& Bahasa Arab edisi juni 2021

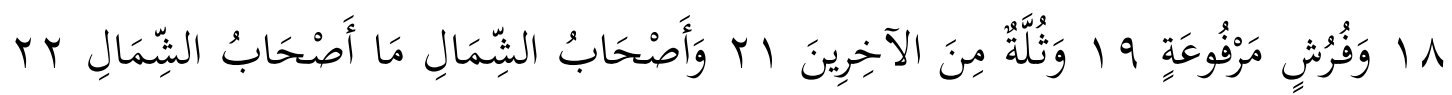

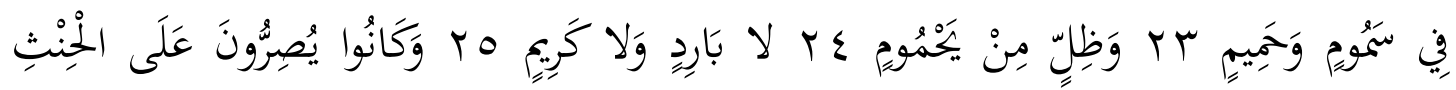

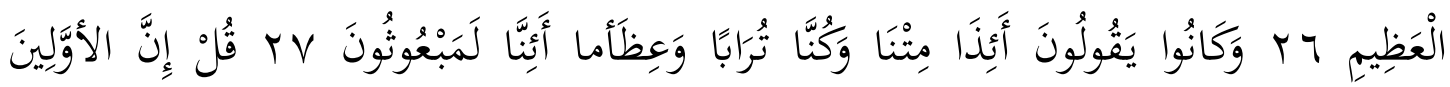

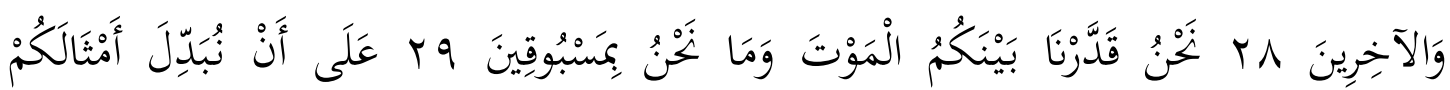

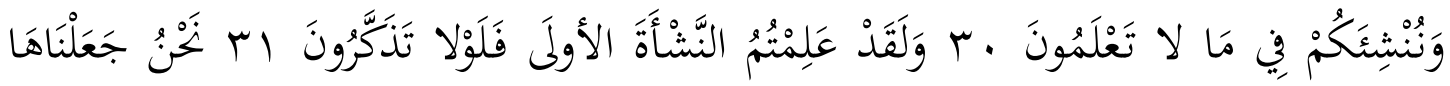

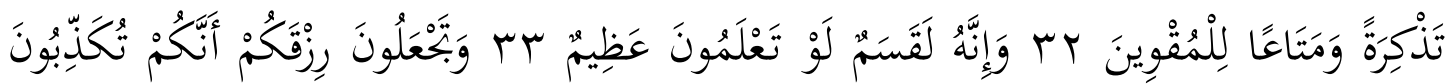

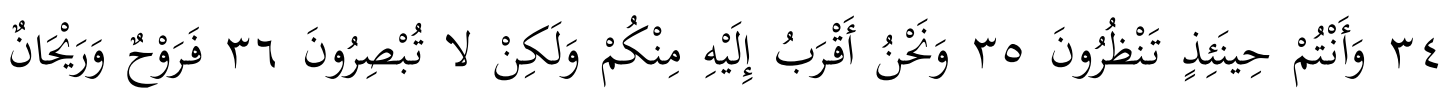

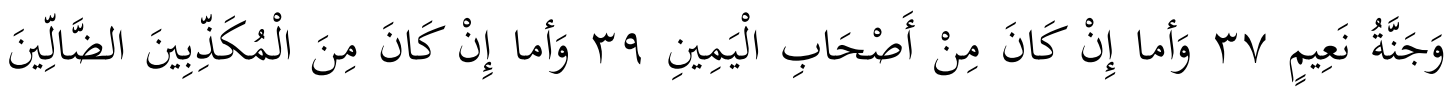

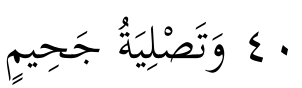

\section{Y. إستراتيجيت تعليم حروف الواو في اللغة العربية}

الحروف العربية بعدة خصائص تميزها عن الحروف اللاتينية. ومن بين هذه الاختلافات أن الحروف العربية هي حرفية، بمعنى أها لا تتعرف على أحرف العلة لأن جميع الحروف هي أحرف ساكنة. الاختلاف الآخر هو الطريقة التي تكتب بها وتقرأها من اليمين إلى اليسار. يعتبر هذا الاختلاف مشكلة في حد ذاته في تعلم اللغة العربية للطلاب الذين يعرفون الحروف اللاتينية فقط،

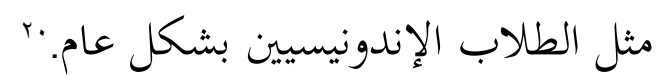

الحرف لايفهمون اذا ليس كاملا ومالديه المعني، اذا سيفهمون هذا المعني بيواصل أي الحرف قبله ويفهمون من الكلمات كاملا. 
Thariqah Ilmiah: Jurnal Ilmu-IImu Kependidikan \& Bahasa Arab edisi juni 2021

المفردات هي أحد عناصر اللغة التي يجب أن يتقنها متعلمي اللغة الاغربية من لمهيرة المكفة في التواصل بتلك اللغة. الاول الحرف ويصل الكلمات وبعده المفردات اذا من يقراء او يتكلام يفهمون لأن زيدة من الكلمات قبله.

إستراتيجيت حروف الواو في سورة الواقعة كمثلي واو العطف، واو القسم، واو الحال، واو

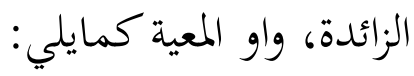

الكلام على الواو العاطفة وهي أما أن تعطف مفردا على مفرد أو جملة على جملة فإذا عطفت جملة على أخرى اشترط أن يكون بينهما تناسب يقتضي المشاركة بالعطف فلا يحسن أن تقول زيد قائم وعمرو شاعر لعدم المناسبة بينهما إلا أن يكون ذلك جوابا لمن أنكر هذين الحكمين أو شك فيهما فتكون قرينة كلامه المتقدم هي المقتضية لجواز العطف بين هاتين الجملتين. أما إستراتيجيت لتعليم اللغة العربية في حرف واو العطف المعلم يعلم الطريق ليفهم ما هو واو العطف، الكلمات يواصل إلى الكلمات بعد, او واو العطف الكلمات قبل وبعده هو جملة الاسمية فهو حرف العطف،عند الحرف العطف الاول الاسم وشكل اخره ضمة، نحو: واللهُ الواو العاطفة جملة أو العاطفة مفردا على مفرد.

واو القسم اسم أقيم مقام المصدر وكثر استعماله فيه والفعل أقسم ومصدره الحقيقي الإقسام

والذي ذكره كثير من أئمة اللغة أن القسم مأخوذ من أيمان القسامة وهي التي يحلف بها في القتل ثم "الفصول المفيدة في الواو المزيدة، صلاح الدين أبو سعيد خليل، ، 99 1، ج. الحح.00. 
Thariqah IImiah: Jurnal IImu-IImu Kependidikan \& Bahasa Arab edisi juni 2021

إنه قيل لكل يمين. بr واو القسم هو حرف جر، يجر الاسم الظاهر لا الضمير، وجوابه لايكون الا جملة خبرية، متعلق بفعل اقسم المحذوف. واو الحال وتسمى أيضا واو الابتداء وهي الداخلة على الجملة التي تقع حالا وكل ما صح من الجمل أن يكون خبرا لمبتدأ أو صلة لموصول أو صفة صح أن تقع حالا. أما إستراتيجيت لتعليم اللغة العربية في حرف واو الحال هو الواو الداخلة على جملة اسمية أو فعلية مسبقتين بمعرفة مثال : زارين أخي و هو مسرور.كيفية لتعريف واو الحال هو غالبا ينظر إلى جملة الكلمات يفارق الواو كمثلي اذا جملة الاول جملة الفعلية وجملة بعد جملة الاسمية. واو الحال بمعنى إذ، وتدخل على جملة الاسمية أو فعلية، أما حرف واو الحالية هو حرف مبني على الفتح لامحل له من الإعراب. وجملته بعدها في محل نصب حال. أما إستراتيجيت لتعليم اللغة العربية في حرف واو الإعتراضية هو الكلمتان ينظر بين الكلمات الآخر، او يوجد الكلمات بين الكلماتين، واو الاعتراضية هو يتصل بجملة المعترضة بين القسم الكلام، والتي لا محل له من لإعراب.

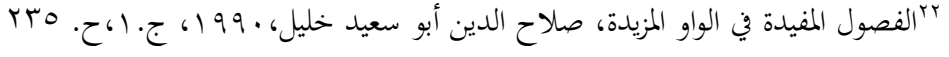

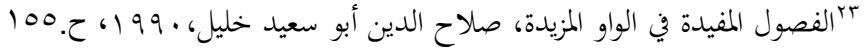


Thariqah IImiah: Jurnal IImu-IImu Kependidikan \& Bahasa Arab edisi juni 2021

الخلاصة

في سورة الواقعة، اياته 97 وجدت الباحثة حروف "الواو" فيها بـ وهذا الجزء VY من القرآن ـ أما حروف "الواو" في سورة الواقعة هو: واو العطف، أما عدد حرف واو العطف في سورة الواقعة مץ. و واو الحال، أما عدد حرف واو الحال في سورة الواقعة ب. واو القسم، أما عدد حرف واو القسم في سورة الواقعة ا. واو المزيدة، أما عدد حرف واو المزيدة في سورة الواقعة ا وإسترابتيت في تعليم اللغة العربية هو إستراتيجيت مفردات، إستراتيجيت نحو أو تراكيب، إستراتيجيت استماع، إستراتيجيت كلام، إستراتيجيت قرائة، إستراتيجيت كتابة، أختار الباحثة من إسترابتية تراكيب. 
Thariqah Ilmiah: Jurnal Ilmu-IImu Kependidikan \& Bahasa Arab

edisi juni 2021

$$
\begin{aligned}
& \text { المراجع }
\end{aligned}
$$

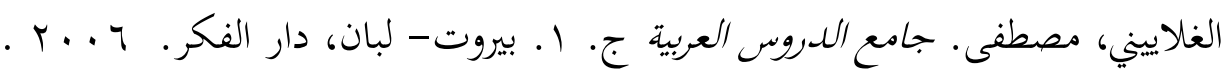

$$
\begin{aligned}
& \text { صلاح الدين كيكلدي العلائي، الفصول المفيدة في الواو المزيدة، دار البشير عمان الطبعة الأولى، . } 99 \text { 1. } \\
& \text { النيسابوري، تفسير النيسابوري، الكتاب مرقم آليا غير موافق للمطبوع. } \\
& \text { أبو الفداء إسماعيل، تفسير القرآن العظيم، دار طيبة للنشر والتوزيع جز } 999 \text { 196. } \\
& \text { أوريل بحرالدين، مهارة التدريس نحو إعداد مدرس اللغة العربية الكفاء، مولانا مالك إبراهيم. } \\
& \text { الهاشمي، أحمد. القواعد الاماسية للغة العربية. بيروت-لبنان: وار الكتب العلمية. } \\
& \text { فتح التقدير، الشوكاني، الكتاب مرقم آليا غير موافق للمطبوع، جوز V. } \\
& \text { طاهر يوسف الطيب، المعجم المفصل في الإعراب، الحرمين سنقافرة جدة اندونسي } \\
& \text { الأمام الصنهاجى، متن الاجرمية،سومبر علم جاي ميدان. } \\
& \text { الكلام على واو احال، فصل نوع الثاني،جز، } 1 . \\
& \text { المعجم الوسط، باب الواو، جز، بـ. } \\
& \text { تفسر ابن ابي زمنين، سورة الواقعة، جز، r. } \\
& \text { صلاح الدين أبو سعيد خليل الفصول المفيلة في الواو المزيلة، ، } 99 \text { 19، جز، } 1 \text {. }
\end{aligned}
$$

Ahmad Puad Efendy, Metodologi Pengajaran Bahasa Arab Malang Misykat 2012.

Abu Razin ,Ummu Razin, Ilmu Nahwu untuk Pemula Jakarta Pustaka Bisa, 2015

Baidan Nashruddin, Metode Penafsiran Ayat. Yogyakarta Pustaka Pelajar,2002.

Diena Millatunnisa Hanifa," Analisis Fungsi Dan Hruf Wawu Dalam Alqur'an','Skripsi Universitas Pendidikan Indonesia,2007.

Hastuti Fitri," Analisi nahwu tentang huruf wawu” Skripsi Thesis, Riau: Universitas Islam Negeri Sultan Syarif Kasim,2014

Hasna Qonita Khansa, Strategi Pembelajaran Bahasa Arab, Universitas Negri Malang, 2016

Husnatul Hamidiyah Analisis Huruf Ma Dalam Suroh Annisa" Skripsi, Padangsidimpuan : IAIN Padangsidimpuan, 2019.

Ismail Bin Katsir. Tafsir Ibnu Katsir Jilid 8 \& 9. Pustaka Imam Syafi'i.

Mustofa, Syaiful. Strategi Pembelajaran Bahasa Arab Inovatif. Malang UIN Maliki Press, 2011.

Mohammad Syarif Sumanti, Strategi Pembelajarn Teori Dan Praktek di Tingkat Pendidikan Dasar. Jakarta:Rajawali, Prees, 2016

Plus, Irhas Dan Khairul Bahri. Kaidah Ilmu Nahwu Dan Contoh I'robnya. Medan Wal Ashri Publishing. 2012.

Rusdianto, Belajar Bahasa Arab Secepat Kilat, Yogyakarta, DIVA Press, 2015

Sutrisno Hadi, Metodologi Research Yogyakarta: Press, 1982.

.Shihab, M. Quraish. Tafsir Al-Misbah. Jakarta Lentera Hati. 2002.

Iman Saiful Mu'minin, Kamus Ilmu Nahwu dan Shorof, Jakart a, AMZAH, 2008. 